\title{
Depressive Symptoms and Food Intake among Weight-Preoccupied Women: Do Eating Behaviors and Attitudes or BMI Mediate This Association?
}

\author{
Julie Maltais-Giguère ${ }^{1}$, Catherine Bégin², Marie-Pierre Gagnon-Girouard ${ }^{3}$, \\ Mélodie Daoust ${ }^{2}$, Véronique Provencher ${ }^{1}$ \\ ${ }^{1}$ Institute of Nutrition and Functional Foods, Université Laval, Québec, Canada \\ ${ }^{2}$ School of Psychology, Université Laval, Québec, Canada \\ ${ }^{3}$ Department of Psychology, Université du Québec à Trois-Rivières, Trois-Rivières, Canada \\ Email: veronique.provencher@fsaa.ulaval.ca
}

Received 23 September 2014; revised 8 November 2014; accepted 23 November 2014

Copyright (C) 2014 by authors and Scientific Research Publishing Inc.

This work is licensed under the Creative Commons Attribution International License (CC BY). http://creativecommons.org/licenses/by/4.0/

(c) (i) Open Access

\section{Abstract}

Associations between depressive symptoms, dysfunctional eating behaviors and attitudes, higher food intake and body mass index (BMI) have been previously observed. However, few studies have assessed these variables in the same study. The first objective is to compare, in a natural setting environment, the profile of women reporting lower or higher levels of depressive symptoms in terms of food intake, eating behaviors and attitudes, and BMI. The second objective is to test mediational models for which the link between depressive symptoms and food intake would be mediated by eating behaviors and attitudes or BMI. Weight-preoccupied women were recruited $(\mathrm{n}=$ 323), and their level of depressive symptoms was assessed using the Beck Depression Inventory. The median score was used to create two groups (lower $\leq 13$; higher $>13$ ). A web-based foodfrequency questionnaire, the Three-Factor Eating Questionnaire, and the Intuitive Eating Scale were completed. BMI was calculated from reported body weight and height. Compared to women with a lower level of depressive symptoms, those with a higher level of depressive symptoms reported a higher energy intake $(p=0.02)$, and a higher consumption of savoury foods $(p=0.02)$. These women also had higher scores of disinhibition $(p<0.0001)$ and susceptibility to hunger $(p=$ 0.0002), ate less intuitively $(p<0.03)$, and had a higher BMI $(p=0.005)$. Association between depressive symptoms and energy intake was mediated by disinhibition, susceptibility to hunger and eating for physical rather than emotional reasons, while the role of BMI was less clear. Regarding another component of food intake, association between depressive symptoms and consumption of savoury foods was mediated by disinhibition and eating for physical rather than emotional reasons. In summary, it seems essential to be aware of the presence of depressive symptoms and 
to pay attention to eating behaviors and attitudes in interventions among weight-preoccupied women.

\title{
Keywords
}

\author{
Depressive Symptoms, Food Intake, Eating Behaviors and Attitudes, Body Mass Index, Women
}

\section{Introduction}

Since more than one decade, the World Health Organization reported an increased prevalence of obesity, which has a major impact on physical and psychological health as well as public health implications [1]. In Canada, $29.5 \%$ of women are overweight and $23.6 \%$ are obese [2]. In accordance with the thin ideal model promoted by our North American society, preoccupation about weight is widespread, especially among women, as they are more likely to attempt to lose weight or to attempt to maintain their weight than men [3]. Depression is also an emerging clinical concern with regards to weight-related problems. In comparison to both non-obese men and women, overweight and obese women are more prone to report depression concurrently to their weight problems, suggesting that an association is observed between obesity and depression, and that this association could be more typically feminine [4]-[7]. The literature also supports that the association between obesity and depression could be bidirectional [4] [6] [8]. In fact, women who report higher depressive symptoms presented a higher body mass index (BMI) [9]-[15], and a higher waist circumference [10] compared to those with lower depressive symptoms. Overall, these results indicate the presence of significant associations between depressive symptoms and BMI, and women appear to be more vulnerable than men. Nevertheless, all overweight and obese women do not necessarily report depressive symptoms, which underline the need to identify other factors that could be associated with depression.

Apart from significant associations with anthropometric measures [16]-[23], eating behaviors and attitudes have also been associated to depressive symptoms. The presence of depressive symptoms has been positively associated with specific eating psychopathology [24], as well as to dysfunctional eating behaviors and attitudes [10] [15] [25] [29], as assessed by the Three-Factor Eating Questionnaire (TFEQ). For example, depressive symptoms have been associated with disinhibition [25]-[28], emotional susceptibility to disinhibition (a subscale of disinhibition)[10], emotional eating [15] [29], susceptibility to hunger [25] [27] [28], but not with cognitive dietary restraint[25] [26] [28]. In addition, cluster groups formed on the basis of lower and higher negative affect (defined as low self-esteem and high depressive symptoms) have shown that women characterized by a higher negative affect ate more after a negative mood induction than the lower negative affect group, suggesting that these women could be more vulnerable to overeating [30]. While questionnaires, such as the TFEQ, are assessing the presence of dysfunctional eating behaviors and attitudes (pathology-focused), it could be of interest to better characterised adaptive eating behaviors and attitudes that can positively contribute to health (health-focused). Accordingly, the Intuitive Eating Scale (IES) has been developed to assess factors related to intuitive eating. Intuitive eating is defined as eating based on physiological hunger and satiety cues rather than external and emotional cues [31]. While intuitive eating has been negatively associated with BMI [31] [32], less is known regarding its association with depressive symptoms.

In addition, some studies have shown that the presence of depressive symptoms was associated with less healthy food choices [10] [29] [33]-[37]. For example, depressive symptoms have been associated with a higher consumption of sweet and non-sweet energy-dense foods and a lower consumption of vegetables and fruits [10]. The association between depressive symptoms and the consumption of sweet foods although became non-significant after adjustment for emotional susceptibility to disinhibition [10]. This finding indicates that particular eating behaviors and attitudes could mediate the association between depressive symptoms and food intake. In another study [29], emotional eating was associated with higher consumption of sweet-and-fatty energy-dense snacks. However, these associations were stronger in women with depressive symptoms compared with those without depressive symptoms[29]. These results thus underline the need to extend our scientific knowledge by identifying factors that may be involved in the association between depressive symptoms and food intake. 
In sum, to our knowledge, associations between depressive symptoms, food intake, eating behaviors and attitudes, and BMI have not been often assessed within the same study, and limited data exist about which factors may influence depressive symptoms. From a clinical standpoint, it is important to empirically document the process that leads to higher food intake, and to conduct this in a natural setting environment that represents what the majority of women seeking for treatment are doing. In that context, the present study aims at assessing the associations between depressive symptoms, food intake, eating behaviors and attitudes, and BMI in natural setting among women. The first objective is to compare the profile of women who reported a lower level of depressive symptoms to those reporting a higher level in terms of food intake, eating behaviors and attitudes, and BMI. The second objective is to test mediational models for which the link between depressive symptoms and food intake is mediated by eating behaviors and attitudes or BMI.

\section{Material and Methods}

\subsection{Participants}

The study was conducted among a sample of 326 women who voluntarily agreed to participate in the research project and who were recruited in the province of Quebec, Canada. All women included in this study were aged 18 and over and were seeking help for weight-related problems in health and social service centers in Quebec (CSSS). They were referred to the Choisir de maigrir? (CdeM?) program [38], which is based on a "Health-AtEvery-Size” (HAES) approach [39]. Considering the natural setting of the present study and the fact that the intervention was occurring outside of the researchers' control, no stringent inclusion or exclusion criteria were determined. However, three women were excluded from the analyses because they were pregnant, for a remaining total of 323 participants. Each woman who participated in the study had to complete several questionnaires evaluating depressive symptoms and eating behaviors and attitudes. After returning these questionnaires by mail, they were invited to complete a web-based food-frequency questionnaire to evaluate food intake. For the analyses related to food intake, nine women were excluded because the delay between the completion of their first questionnaires and the web-based food-frequency questionnaire was too long (i.e., more than 45.4 days, which corresponds to more than two standard deviations from the mean). We thus considered that these women have been too much exposed to the CdeM? program by the time they completed the food-frequency questionnaire. Prior to their participation to the study, each woman signed an informed consent document which was approved by the Agence de la santé et des services sociaux de Montréal Research Ethics Committee.

\subsection{Study Design}

Women who participated in the present study were recruited during four phases (September 2010, January 2011, March 2011, and September 2011), in which the same assessment and intervention were performed. This paper does not present any results from the intervention part of the study but only results obtained from baseline measurements.

\subsection{Measures}

\subsubsection{Depressive Symptoms}

The Beck Depression Inventory-II (BDI; 21 items) [40] measures the intensity of depressive symptoms. Each item is scored on a 4-point Likert scale ranging from 0 to 3, and then summed. A higher score indicates higher depressive symptoms. The clinical cut-offs of the BDI are as follow: 0 - 13: minimal; 14 - 19: mild; 20 - 28 : moderate; $\geq 29$ : severe depressive symptoms. The BDI presents a high internal consistency and an adequate validity [40].

\subsubsection{Food Intake}

Self-reported dietary intakes were assessed by a self-administered web food-frequency questionnaire (FFQ; 136 items) [41]. This questionnaire evaluates food intake over the last month. Participants were first asked to recall the frequency of consumption of an individual food item or group of foods with similar characteristics in terms of day, week or month. Answer choices offered between eight and nine continuous responses ranging from "never" to "four or more times per day". Participants had also to select a portion size (two to four different sizes). 
The Nutrition Data System for Research (software version 4.03, Food and Nutrient Database 31, Minneapolis, MN, USA) and the Canadian Nutrient File (CNF, version 2007b, Ottawa, ON, Canada) were used to create a food composition database for the analysis of data derived from the web-FFQ. Then, these databases were used to calculate total energy (kcal), lipids (\% energy), proteins (\% energy), carbohydrates (\% energy) and alcohol (\% energy) intakes. Two food groups were also formed: savoury foods (i.e. french fries; potato and corn chips; crackers; pizza; poutine; corndog; egg and imperial rolls; parmesan fondue; popcorn; pretzels) and sweet foods (i.e. frozen yogurt, ice milk and sorbet; ice cream, ice cream bars and sundae; chocolate; candies; cookies; cake and brownies; pie; doughnuts; other pastries). These foods groups were formed by calculating the mean daily consumption of each food item in the respective group. The web-FFQ presents satisfying validity and good reproducibility for assessing nutrient intakes [41].

\subsubsection{Eating Behaviors and Attitudes}

Attitudes and behaviors related to eating were measured by two validated questionnaires. The Three-Factor Eating Questionnaire (TFEQ; 51 items) [42] assesses three factors that refer to cognitions and behaviors associated with eating. These factors are cognitive dietary restraint, disinhibition and susceptibility to hunger. Cognitive dietary restraint (21 items) is a conscious control of food intake with concerns about shape and weight. Disinhibition (16 items) is an overconsumption of food in response to a variety of stimuli associated with a loss of control on food intake. Susceptibility to hunger (14 items) refers to food intake in response to feelings and perceptions of hunger. The response format of the TFEQ is varied with yes/no questions and 4-point Likert scale. A higher score indicates higher level in each subscale. This questionnaire is validated [42]-[44], and presents good criterion validity, test-retest reliability and predictive validity [42].

The Intuitive Eating Scale (IES; 21 items) [31] assesses three factors that refer to the concept of intuitive eating. These factors are unconditional permission to eat, eating for physical rather than emotional reasons, and reliance on internal hunger and satiety cues. Unconditional permission to eat (9 items) assesses the willingness to eat when physiologically hungry and in accordance with food that is desired at the moment. Eating for physical rather than emotional reasons (6 items) refers to the tendency to eat to satisfy an internal hunger drive rather than to cope with emotional fluctuations and/or distress. Reliance on internal hunger and satiety cues (6 items) refers to the degree of awareness of internal hunger and satiety signals and the ability to use these signals to guide eating behavior. The response format is a 5-point Likert scale ranging from 1 (strongly disagree) to 5 (strongly agree). A higher score indicates higher level of intuitive eating. The IES factors present good internal consistency and a 3 weeks test-retest reliability [31].

\subsubsection{Anthropometric Measurements}

Height and body weight were reported by the participants and BMI was then calculated. For a subgroup of women $(n=151)$, height and body weight were also measured by the health professionals who were leading the CdeM? program, and BMI was calculated. A Spearman's correlation was conducted between the reported and the measured BMI. The use of the reported BMI for the analyses of this study is justified by the number of data available for this variable $(\mathrm{n}=321)$ and by the strong correlation $(\mathrm{r}=0.92 ; p<0.0001)$ observed between the two BMI measures.

\subsection{Statistical Analyses}

For the first objective, the median score of the BDI was used to create two groups of depressive symptoms: lower $(\leq 13)$ and higher $(>13)$ levels. Univariate analyses of variance (ANOVA) were performed to assess the differences between these two groups in terms of food intake and BMI. To assess the difference in terms of eating behaviors and attitudes between women with a lower level of depressive symptoms to those reporting a higher level of symptoms, a multivariate analysis of variance (MANOVA) was conducted. In line with the second objective, Pearson's and Spearman's correlation analyses were performed to assess the associations between depressive symptoms (independent variable), food intake (dependent variable), eating behaviors and attitudes (mediator), and BMI (mediator). To evaluate the mediating role of eating behaviors and attitudes or BMI in the association between depressive symptoms and food intake, series of regression analyses were conducted as proposed by Baron and Kenny [45]. Three conditions were necessary to conclude to a mediational association: 1) the independent variable (depressive symptoms) significantly predicted the mediator (eating behaviors and attitudes or BMI); 2) the independent variable (depressive symptoms) significantly predicted the dependant varia- 
ble (food intake) and 3) the entry of the mediator (eating behaviors and attitudes or BMI) in the regression equation completely (full mediational model) or substantially (partial mediational model) reduced the strength of the link between the independent variable (depressive symptoms) and the dependant variable (food intake). For variables not normally distributed, a log transformation was performed (ANOVA and MANOVA) or Spearman's correlation analyses were performed. The probability level for significance used for the interpretation of all statistical analyses was set at an alpha level of $p \leq 0.05$. All analyses were performed by using SAS statistical software (version 9.2, SAS Institute, Cary, NC, USA).

\section{Results}

Characteristics of women included in the study are presented in Table 1. Participants' mean age was $50.3 \pm 11.9$ years. The BMI range of 22.3 to $64.6 \mathrm{~kg} / \mathrm{m}^{2}$ shows that the sample was almost entirely composed of overweight and obese women (BMI $<25 \mathrm{~kg} / \mathrm{m}^{2}, \mathrm{n}=7 ; 25 \mathrm{~kg} / \mathrm{m}^{2} \leq \mathrm{BMI}<30 \mathrm{~kg} / \mathrm{m}^{2}, \mathrm{n}=68 ; 30 \mathrm{~kg} / \mathrm{m}^{2} \leq \mathrm{BMI}<35 \mathrm{~kg} / \mathrm{m}^{2}, \mathrm{n}=$ $100 ; 35 \mathrm{~kg} / \mathrm{m}^{2} \leq \mathrm{BMI}<40 \mathrm{~kg} / \mathrm{m}^{2}, \mathrm{n}=81 ; \mathrm{BMI} \geq 40 \mathrm{~kg} / \mathrm{m}^{2}, \mathrm{n}=65$ ). The mean level of depressive symptoms was $15.6 \pm 11.3$ (range of 0 to 49 ), which correspond to the presence of mild depressive symptoms according to the clinical cut-offs of the BDI [40]. The mean energy intake was $2548.1 \pm 1123.7 \mathrm{kcal}$ and the proportion of lipids, proteins, carbohydrates and alcohol was $35.8 \pm 6.0 \%, 17.4 \pm 3.1 \%, 45.4 \pm 6.9 \%$ and $1.4 \pm 2.3 \%$, respectively. Individuals from each level of education and familial income were represented in the study.

Table 2 presents the means for food intake, eating behaviors and attitudes, and BMI of women with lower or higher levels of depressive symptoms. Compared to women with a lower level of depressive symptoms, those with a higher level of depressive symptoms reported a higher energy intake and a higher consumption of savoury foods. No significant difference was observed for the proportion of lipids, proteins and carbohydrates and for the consumption of sweet foods. Eating behaviors and attitudes were also significantly different between lower and higher levels of depressive symptoms ( $\mathrm{F}=6.49$; $p<0.0001)$. More precisely, disinhibition and susceptibility to hunger scores were higher among women with a higher level of depressive symptoms, while cognitive dietary restraint score was not different between groups. Women with a higher level of depressive symptoms also ate less intuitively, i.e. they gave themselves less unconditional permission to eat, they ate less for physical reasons and more for emotional reasons, and they relied less on their hunger and satiety cues. Finally, women with higher level of depressive symptoms also reported a higher BMI.

Analyses were performed to evaluate the mediating role of eating behaviors and attitudes in the association between depressive symptoms and food intake. In accordance with the required conditions of Baron and Kenny (as described in the Section 2.4. Statistical Analyses), we were allowed to test six models. Significant results for the five models retained are shown in Table 3. The addition of disinhibition as a mediator had a full effect on the association between depressive symptoms and energy intake, decreasing the $\beta$ coefficient from 0.17 to 0.09 , a $48.6 \%$ reduction (Sobel test $=2.95, p=0.003$ ), with an overall percentage of explained variance of $7 \%$ for the final model. The addition of susceptibility to hunger as a mediator had a full effect on the association between depressive symptoms and energy intake, decreasing the $\beta$ coefficient from 0.17 to 0.11 , a $33.8 \%$ reduction (Sobel test $=2.41, p=0.02$ ), with an overall percentage of explained variance of $6 \%$ for the final model. The addition of IES-Eating for physical rather than emotional reasons as a mediator had a full effect on the association between depressive symptoms and energy intake, decreasing the $\beta$ coefficient from 0.17 to 0.10 , a $44.2 \%$ reduction (Sobel test $=2.80, p=0.005$ ), with an overall percentage of explained variance of $7 \%$ for the final model. The addition of disinhibition as a mediator had a partial effect on the association between depressive symptoms and consumption of savoury foods, decreasing the $\beta$ coefficient from 0.24 to 0.17 , a $27.4 \%$ reduction (Sobel test $=2.41, p=0.02$ ), with an overall percentage of explained variance of $8 \%$ for the final model. The addition of IES-Eating for physical reasons rather than emotional reasons as a mediator had a partial effect on the association between depressive symptoms and consumption of savoury foods, decreasing the $\beta$ coefficient from 0.25 to 0.19 , a $23.0 \%$ reduction (Sobel test $=2.20, p=0.03$ ), with an overall percentage of explained variance of $8 \%$ for the final model. The addition of susceptibility to hunger as a mediator had no effect on the association between depressive symptoms and consumption of savoury foods, because the Sobel test was not significant $(p=0.10)$.

Analyses were also performed to test whether BMI could mediate the associations between depressive symptoms and food intake. In accordance with the required conditions of Baron and Kenny (as described in the Section 2.4. Statistical Analyses), we were allowed to test two models. Significant result for the model retained is shown in Table 4. The addition of BMI as a mediator had a partial effect on the association between depressive 
Table 1. Characteristics of women included in the study $(n=323)$.

\begin{tabular}{|c|c|c|c|c|}
\hline & Means & SD & Minimum & Maximum \\
\hline Age (years) & 50.3 & 11.9 & 19.0 & 83.0 \\
\hline BMI $\left(\mathrm{kg} / \mathrm{m}^{2}\right)$ & 35.4 & 7.0 & 22.3 & 64.6 \\
\hline \multicolumn{5}{|l|}{ Education level (\%) } \\
\hline No scolarity & 0 & - & - & - \\
\hline Primary school & 4.0 & - & - & - \\
\hline Secondary School & 32.8 & - & - & - \\
\hline College $^{\mathrm{a}}$ & 29.7 & - & - & - \\
\hline University $^{\mathrm{a}}$ & 32.5 & - & - & - \\
\hline Prefer not to answer & 0.9 & - & - & - \\
\hline \multicolumn{5}{|l|}{ Familial income (\%) } \\
\hline $0-19,000 \$$ & 11.5 & - & - & - \\
\hline $20,000-39,999 \$$ & 28.9 & - & - & - \\
\hline $40,000-59$ 999\$ & 16.8 & - & - & - \\
\hline $60,000-79,999 \$$ & 11.5 & - & - & - \\
\hline $80,000-99,999 \$$ & 8.7 & - & - & - \\
\hline More than $100,000 \$$ & 12.1 & - & - & - \\
\hline Prefer not to answer & 10.6 & - & - & - \\
\hline Beck Depression Inventory & 15.6 & 11.3 & 0 & 49.0 \\
\hline \multicolumn{5}{|l|}{ Food intake ${ }^{\mathrm{b}}$} \\
\hline Energy intake (kcal) & 2548.1 & 1123.7 & 630.8 & 10341.9 \\
\hline Lipids (\% energy) & 35.8 & 6.0 & 17.6 & 57.0 \\
\hline Proteins (\% energy) & 17.4 & 3.1 & 10.5 & 27.5 \\
\hline Carbohydrates (\% energy) & 45.4 & 6.9 & 25.5 & 68.3 \\
\hline Alcohol (\% energy) & 1.4 & 2.3 & 0 & 12.4 \\
\hline Savoury foods (use-frequency/day) & 1.4 & 1.4 & 0 & 8.6 \\
\hline Sweet foods (use-frequency/day) & 2.5 & 3.3 & 0 & 21.8 \\
\hline \multicolumn{5}{|l|}{ Eating behaviours and attitudes } \\
\hline Cognitive dietary restraint & 8.9 & 3.9 & 1.0 & 19.0 \\
\hline Disinhibition & 9.7 & 3.2 & 1.0 & 16.0 \\
\hline Susceptibility to hunger & 7.0 & 3.9 & 0 & 14.0 \\
\hline IES-Unconditional permission to eat & 2.7 & 0.7 & 1.1 & 4.6 \\
\hline IES-Eating for physical reasons & 2.4 & 1.0 & 1.0 & 5.0 \\
\hline IES-Reliance on hunger/satiety cues & 3.0 & 0.8 & 1.0 & 5.0 \\
\hline
\end{tabular}

a. In the province of Quebec (Canada), college correspond to CEGEP, a post-secondary institution where people pursue either pre-university or professional degrees. b. $\mathrm{n}=243$ participants for variables related to food intake. SD: standard deviation; BMI: body mass index; IES: Intuitive Eating Scale. 
Table 2. Differences for food intake, eating behaviors and attitudes, and BMI among women presenting lower or higher levels of depressive symptoms.

\begin{tabular}{|c|c|c|c|c|c|c|c|}
\hline \multirow[b]{3}{*}{ Beck Depression Inventory ${ }^{\mathrm{a}}$} & \multicolumn{7}{|c|}{ Levels of depressive symptoms } \\
\hline & \multicolumn{3}{|c|}{ Lower } & \multicolumn{3}{|c|}{ Higher } & \multirow[b]{2}{*}{${ }^{* * *}$} \\
\hline & 6.7 & \pm & 3.9 & 24.7 & \pm & 9.0 & \\
\hline \multicolumn{8}{|l|}{ Food intake $^{\mathrm{b}}$} \\
\hline Energy intake (kcal) & 2376.9 & \pm & 903.4 & 2723.5 & \pm & 1292.3 & * \\
\hline Lipids (\% energy) & 35.1 & \pm & 6.2 & 36.5 & \pm & 5.8 & \\
\hline Proteins (\% energy) & 17.7 & \pm & 3.3 & 17.2 & \pm & 2.9 & \\
\hline Carbohydrates (\% energy) & 45.6 & \pm & 7.3 & 45.2 & \pm & 6.6 & \\
\hline Savoury foods (use-frequency/day) & 1.2 & \pm & 1.1 & 1.7 & \pm & 1.7 & * \\
\hline Sweet foods (use-frequency/day) & 2.2 & \pm & 2.7 & 2.8 & \pm & 3.8 & \\
\hline \multicolumn{8}{|l|}{ Eating behaviors and attitudes ${ }^{\mathrm{c}}$} \\
\hline Cognitive dietary restraint & 8.9 & \pm & 4.2 & 8.8 & \pm & 3.6 & \\
\hline Disinhibition & 8.9 & \pm & 3.1 & 10.6 & \pm & 3.1 & $* * * *$ \\
\hline Susceptibility to hunger & 6.2 & \pm & 3.8 & 7.8 & \pm & 4.0 & ${ }^{* * *}$ \\
\hline IES-Unconditional permission to eat & 2.9 & \pm & 0.7 & 2.6 & \pm & 0.6 & $* * *$ \\
\hline IES-Eating for physical reasons & 2.7 & \pm & 1.0 & 2.1 & \pm & 1.0 & ${ }^{* * * *}$ \\
\hline IES-Reliance on hunger/satiety cues & 3.2 & \pm & 0.8 & 3.0 & \pm & 0.8 & ${ }^{*}$ \\
\hline BMI $\left(\mathrm{kg} / \mathrm{m}^{2}\right)^{\mathrm{a}}$ & 34.3 & \pm & 6.4 & 36.5 & \pm & 7.4 & ** \\
\hline
\end{tabular}

Means \pm standard deviation; Significantly different from lower level of depressive symptoms: ${ }^{*} p<0.05 ;{ }^{* *} p<0.01 ;{ }^{* * *} p<0.001 ;{ }^{* * * *} p<0.0001$. a. ANOVA were conducted for Beck Depression Inventory and BMI; Lower: $\mathrm{n}=163$ and Higher: $\mathrm{n}=159$. b. ANOVA were conducted for food intake; Lower: $\mathrm{n}=123$ and Higher: $\mathrm{n}=120$. c. MANOVA were conducted for eating behaviors and attitudes; Lower: $\mathrm{n}=155$ and Higher: $\mathrm{n}=150$. BMI: body mass index; IES: Intuitive Eating Scale.

symptoms and energy intake, decreasing the $\beta$ coefficient from 0.17 to 0.13 , a $22.8 \%$ reduction (Sobel test $=$ 1.98, $p=0.05$ ), with an overall percentage of explained variance of $10 \%$ for the final model. The addition of BMI as a mediator had no effect on the association between depressive symptoms and consumption of savoury foods, because the Sobel test was not significant $(p=0.06)$.

\section{Discussion}

The present study aimed at evaluating, in a natural setting environment, the link between depressive symptoms, food intake, eating behaviors and attitudes, and BMI among a group of weight-preoccupied women. With regards to food intake, results showed that the presence of a higher level of depressive symptoms was associated with overconsumption of food, as noted by higher energy intake and higher consumption of savoury foods. Our results are among the first to show a significantly positive association between depressive symptoms and energy intake. These results are also concordant with the literature, as associations between depressive symptoms and less healthy food choices have been previously demonstrated [10] [29] [33]-[37]. For example, depressive symptoms have been associated to more calories for each gram of food and beverages consumed [35], and to higher consumption of fast-food [33], sweet-and-fatty energy dense snacks [29] and non-sweet energy-dense foods [10]. However, unlike previous results from Konttinen et al. [10], the consumption of sweet foods was not significantly different between women with lower and higher levels of depressive symptoms. Cultural differences, which may explain the disparity in the foods used to create the groups based on the FFQ analysis (e.g. sweet and savoury foods in the present study conducted in the province of Quebec, Canada vs. sweet and non-sweet foods in the study of Konttinen et al. [10] conducted in Finland), could be suggested as an explanation for this difference. In accordance with our findings, the presence of depressive symptoms has been previously associated with higher levels of disinhibition [25]-[28], 
Table 3. Summary statistics for multiple regression analyses predicting energy intake and savoury foods with eating behaviors and attitudes as a mediator $(n=242)$.

\begin{tabular}{|c|c|c|c|c|c|c|}
\hline \multirow[b]{2}{*}{ Energy intake } & \multirow{2}{*}{$\begin{array}{l}\text { Predictors } \\
1 . \mathrm{BDI}\end{array}$} & \multirow{2}{*}{$\begin{array}{l}\text { Dependent variables } \\
\text { Disinhibition }\end{array}$} & \multirow{2}{*}{$\begin{array}{c}\boldsymbol{\beta} \\
0.37\end{array}$} & \multicolumn{2}{|c|}{ t-value (Sig) } & \multirow{2}{*}{$\begin{array}{c}\mathbf{R}^{2} \\
0.14\end{array}$} \\
\hline & & & & 6.16 & ${ }^{* * * * *}$ & \\
\hline & 2. BDI & Energy intake & 0.17 & 2.70 & ** & 0.03 \\
\hline & 3. BDI & Energy intake & 0.09 & 1.32 & & \\
\hline & Disinhibition & & 0.23 & 3.36 & ${ }^{* * *}$ & \\
\hline \multirow[t]{4}{*}{ Energy intake } & 1. BDI & Susceptibility to hunger & 0.32 & 5.23 & ${ }^{* * * *}$ & 0.10 \\
\hline & 2. BDI & Energy intake & 0.17 & 2.68 & ** & 0.03 \\
\hline & 3. BDI & Energy intake & 0.11 & 1.71 & & \multirow{2}{*}{0.06} \\
\hline & Susceptibility to hunger & & 0.18 & 2.72 & ** & \\
\hline \multirow[t]{4}{*}{ Energy intake } & 1. BDI & IES-physical reasons & -0.36 & -5.95 & $* * * *$ & 0.13 \\
\hline & 2. BDI & Energy intake & 0.17 & 2.71 & ** & 0.03 \\
\hline & 3. BDI & Energy intake & 0.10 & 1.44 & & \multirow{2}{*}{0.07} \\
\hline & IES-physical reasons & & -0.21 & -3.18 & ${ }^{* *}$ & \\
\hline \multirow[t]{4}{*}{ Savoury foods } & 1. BDI & Disinhibition & 0.37 & 6.16 & ${ }^{* * * *}$ & 0.14 \\
\hline & 2. BDI & Savoury foods & 0.24 & 3.76 & ${ }^{* * *}$ & 0.06 \\
\hline & 3. BDI & Savoury foods & 0.17 & 2.57 & * & \multirow{2}{*}{0.08} \\
\hline & Disinhibition & & 0.18 & 2.62 & ** & \\
\hline \multirow[t]{4}{*}{ Savoury foods } & 1. BDI & IES-physical reasons & -0.36 & -5.95 & $* * * *$ & 0.13 \\
\hline & 2. BDI & Savoury foods & 0.25 & 3.93 & $* * * *$ & 0.06 \\
\hline & 3. BDI & Savoury foods & 0.19 & 2.85 & ${ }^{* *}$ & \multirow{2}{*}{0.08} \\
\hline & IES-physical reasons & & -0.16 & -2.37 & * & \\
\hline
\end{tabular}

${ }^{*} p<0.05 ;{ }^{* *} p<0.01 ;{ }^{* * *} p<0.001 ;{ }^{* * * *} p<0.0001 ; \beta=$ standardized coefficients; BDI: Beck Depression Inventory; IES: Intuitive Eating Scale; IES-physical reasons: IES-eating for physical rather than emotional reasons.

Table 4. Summary statistics for multiple regression analyses predicting energy intake with BMI as a mediator $(n=241)$.

\begin{tabular}{|c|c|c|c|c|c|c|}
\hline \multirow[b]{2}{*}{ Energy intake } & \multirow{2}{*}{$\begin{array}{l}\text { Predictors } \\
\text { 1. BDI }\end{array}$} & \multirow{2}{*}{$\begin{array}{l}\text { Dependent variables } \\
\text { BMI }\end{array}$} & \multirow{2}{*}{$\begin{array}{c}\boldsymbol{\beta} \\
0.14\end{array}$} & \multicolumn{2}{|c|}{ t-value (Sig) } & \multirow{2}{*}{$\begin{array}{c}\mathbf{R}^{2} \\
0.02\end{array}$} \\
\hline & & & & 2.22 & $*$ & \\
\hline & 2. BDI & Energy intake & 0.17 & 2.67 & ** & 0.03 \\
\hline & 3. BDI & Energy intake & 0.13 & 2.12 & $*$ & \multirow{2}{*}{0.10} \\
\hline & BMI & & 0.27 & 4.40 & $* * *$ & \\
\hline
\end{tabular}

${ }^{*} p<0.05 ;{ }^{* *} p<0.01 ;{ }^{* * *} p<0.0001 ; \beta=$ Standardized coefficients; BDI: Beck Depression Inventory; BMI: body mass index.

emotional susceptibility to disinhibition [10], emotional eating [15] [29] and susceptibility to hunger [25] [27] [28], but not with cognitive dietary restraint [25] [26] [28]. The subscales of the Intuitive Eating Scale were all negatively associated with the level of depressive symptoms, which suggested that women with higher level of depressive symptoms, or presenting a lower psychological well-being [31], ate less intuitively. This novel result could be explained by the fact that women with higher depressive symptoms may have difficulties to rely and trust themselves. In fact, some symptoms measured by the BDI are associated with indecisiveness, guilt, concentrating difficulty, low self-confidence and low self-efficacy [40]. Finally, a higher BMI was also observed among women with higher levels of depressive symptoms, which is in line with what has been noted previously in the literature [9] [15]. 
Overall, findings from this study showed that women with higher level of depressive symptoms were characterised by a more deleterious nutritional profile and a higher BMI compared to women with lower level of depressive symptoms. The associations observed thus stress the importance to better understand which factors may be related to depressive symptoms.

The second objective of this study was to assess the mechanisms by which depressive symptoms were linked to food intake by examining eating behaviors and attitudes or BMI as potential mediators. Our results showed that the association between depressive symptoms and energy intake was directly (full effect) explained by disinhibition and susceptibility to hunger, and by a lower tendency to eat for physical rather than emotional reasons. Our results also showed that the association between depressive symptoms and consumption of savoury foods was directly and indirectly (partial effect) explained by disinhibition, as well as by a lower tendency to eat for physical rather than emotional reasons. While the models proposed only explain a small percentage of the variance and that other factors are possibly involved in the associations between depressive symptoms and food intake, results from this study suggest that specific eating behaviors and attitudes played an important role in these associations. Accordingly, results from Konttinen et al. [10] have suggested a mediating role of emotional susceptibility to disinhibition in the association between depressive symptoms and consumption of sweet energydense foods. However, this mediating role was not observed for the consumption of non-sweet energy-dense foods [10]. By using mediational models, our natural-setting study reinforced that particular eating behaviors and attitudes could be part of the mechanisms through which depressive symptoms are related to food intake among weight-preoccupied women. Considering this, weight-control strategies that mainly focus on energy-restricted diets, without addressing eating behaviors and attitudes, may be less effective. Interventions should rather focus on eating behaviors and attitudes, by reducing disinhibition and susceptibility to hunger and by increasing eating for physical rather than emotional reasons, in order to facilitate a better regulation of energy intake and improve food choices.

Our results also showed that the association between depressive symptoms and energy intake was directly and indirectly (partial effect) mediated by BMI, while no mediating effect of BMI was observed for the consumption of savoury foods. Note that the mediational effect of BMI on energy intake became non-significant when women with a normal BMI (between 18.5 and $24.9 \mathrm{~kg} / \mathrm{m}^{2} ; \mathrm{n}=7$ ) where excluded from the analysis (data not shown). This result indicates that the role of BMI in the association between depressive symptoms and energy intake is less predominant, particularly among overweight and obese women. To our knowledge, no study has yet assessed the mediating effect of BMI on the associations between depressive symptoms, energy intake and consumption of savoury foods. Nevertheless, Crawford et al. [33] observed that the adjustment for BMI (in addition to other variables such as age, race, education, and income) did not affect the positive association between depressive symptoms and consumption of fast-food, which is clearly in line with our results. Another study showed that the association between depressive symptoms and consumption of non-sweet energy-dense foods was significant despite the adjustment for BMI [10]. In summary, eating behaviors and attitudes, more than BMI, are possibly involved in the associations between depressive symptoms, energy intake and consumption of savoury foods. These findings therefore questioned the relevance of weight-centered interventions among overweight and obese women who are presenting depressive symptoms, as interventions should not only focus on weight loss.

\subsection{Limitations and Strengths}

Some limitations of our study need to be mentioned. First of all, because of the cross-sectional design of the study, no causal link could be established. Therefore, the mediational models that have been assessed remain theoretical, and the causal link between all the variables should be examined using a longitudinal design. The relatively low percentages of explained variance obtained with the models may also limit the implication of the results. Secondly, the presence of a delay between the completion of the first questionnaires and the web-based food-frequency questionnaire was a limit of our study. Ideally, all the questionnaires should have been completed at the same time, but it was not feasible due to methodological constraints. Another limit was the use of self-reported measures to assess depressive symptoms, food intake, eating behaviors and attitudes, and BMI, which may be influenced by potential social desirability bias. On the other hand, this study has also some strengths. For example, the number of participants was relatively high. The combination of more than one questionnaire to assess eating behaviors and attitudes allowed us to make a more complete picture of these variables. In fact, the use of the Intuitive Eating Scale was an advantage, since this recent questionnaire allowed us to eva- 
luate a relatively new concept, which assessed an adaptive eating, compared to more dysfunctional eating behaviors and attitudes as assessed by the TFEQ. The finding that women with higher depressive symptoms ate less intuitively was a novel and interesting result, which provides a better understanding of the nutritional profile of weight-preoccupied women. Finally, the fact that the study was conducted in a natural setting gave a more representative profile of women who are seeking for help with regards to weight management.

\subsection{Conclusion}

In conclusion, findings from this study suggest that the presence of depressive symptoms among weight-preoccupied women is prevalent and is associated with deleterious nutritional profile and higher BMI. Thereby, it seems essential to be aware of the presence of depressive symptoms and to adapt the interventions accordingly. These results also suggest that the associations between depressive symptoms and food intake are mediated by specific eating behaviors and attitudes. From a clinical viewpoint, focusing only on reducing caloric intake or consumption of unhealthy foods, without addressing eating behaviors and attitudes, may not be adequate nutrition strategies among these women. In contrast, improvement in eating behaviors and attitudes by identifying pathways that lead to overeating could improve food choices among weight-preoccupied women presenting depressive symptoms, which could then be more beneficial for long term overall health.

\section{Acknowledgements}

This research project was supported by a Canadian Institutes of Health Research (CIHR) operating grant (Population Health Intervention Research) and by the Heart and Stroke Foundation. At the time the study was conducted, J. M.-G. was a recipient of a scholarship from the Fonds de recherche du Quebec en santé, and V.P. was a research scholar from the Fonds de recherche du Quebec en santé. The authors would like to acknowledge the excellent work of Mylène Turcotte, the research assistant in charge of the coordination of the project. The authors would also like to thank Lyne Mongeau and Marie-Claude Paquette for their implication in the development of the large-scale research project, and the subjects for their participation in the study.

\section{References}

[1] World Health Organization (2000) Obesity: Preventing and Managing the Global Epidemic. Report of a WHO Consultation, Geneva.

[2] Statistique Canada (2010) Enquête canadienne sur les mesures de la santé: Tableaux de données du cycle 1. Ottawa.

[3] Cazale, L., Dufour, R., Mongeau, L. and Nadon, S. (2010) Statut pondéral et utilisation de produits ou moyens amaigrissants. In: Institut de la statistique du Québec_-Gouvernement du Québec, Ed., L'Enquête québécoise sur la santé de la population 2008: Pour en savoir plus sur la santé des Québécois, Québec, 131-157.

[4] Markowitz, S., Friedman, M.A. and Arent, S.M. (2008) Understanding the Relation between Obesity and Depression: Causal Mechanisms and Implications for Treatment. Clinical Psychology: Science and Practice, 15, 1-20. http://dx.doi.org/10.1111/j.1468-2850.2008.00106.x

[5] de Wit, L., Luppino, F., van Straten, A., Penninx, B., Zitman, F. and Cuijpers, P. (2010) Depression and Obesity: A Meta-Analysis of Community-Based Studies. Psychiatry Res, 178, 230-235. http://dx.doi.org/10.1016/j.psychres.2009.04.015

[6] Faith, M.S., Butryn, M., Wadden, T.A., Fabricatore, A., Nguyen, A.M. and Heymsfield, S.B. (2011) Evidence for Prospective Associations among Depression and Obesity in Population-Based Studies. Obesity Reviews, 12, e438-e453. http://dx.doi.org/10.1111/j.1467-789X.2010.00843.x

[7] Atlantis, E. and Baker, M. (2008) Obesity Effects on Depression: Systematic Review of Epidemiological Studies. International Journal of Obesity (London), 32, 881-891. http://dx.doi.org/10.1038/ijo.2008.54

[8] Luppino, F.S., de Wit, L.M., Bouvy, P.F., Stijnen, T., Cuijpers, P., Penninx, B.W. and Zitman, F.G. (2010) Overweight, Obesity, and Depression: A Systematic Review and Meta-Analysis of Longitudinal Studies. Archives of General Psychiatry, 67, 220-229. http://dx.doi.org/10.1001/archgenpsychiatry.2010.2

[9] Carpenter, K.M., Hasin, D.S., Allison, D.B. and Faith, M.S. (2000) Relationships between Obesity and DSM-IV Major Depressive Disorder, Suicide Ideation, and Suicide Attempts: Results from a General Population Study. American Journal of Public Health, 90, 251-257. http://dx.doi.org/10.2105/AJPH.90.2.251

[10] Konttinen, H., Mannisto, S., Sarlio-Lahteenkorva, S., Silventoinen, K. and Haukkala, A. (2010) Emotional Eating, Depressive Symptoms and Self-Reported Food Consumption. A Population-Based Study. Appetite, 54, 473-479. 
http://dx.doi.org/10.1016/j.appet.2010.01.014

[11] Onyike, C.U., Crum, R.M., Lee, H.B., Lyketsos, C.G. and Eaton, W.W. (2003) Is Obesity Associated with Major Depression? Results from the Third National Health and Nutrition Examination Survey. American Journal of Epidemiology, 158, 1139-1147. http://dx.doi.org/10.1093/aje/kwg275

[12] Istvan, J., Zavela, K. and Weidner, G. (1992) Body Weight and Psychological Distress in NHANES I. International Journal of Obesity and Related Metabolic Disorders, 16, 999-1003.

[13] McIntyre, R.S., Konarski, J.Z., Wilkins, K., Soczynska, J.K. and Kennedy, S.H. (2006) Obesity in Bipolar Disorder and Major Depressive Disorder: Results from a National Community Health Survey on Mental Health and Well-Being. Canadian Journal of Psychiatry, 51, 274-280.

[14] Heo, M., Pietrobelli, A., Fontaine, K.R., Sirey, J.A. and Faith, M.S. (2006) Depressive Mood and Obesity in US Adults: Comparison and Moderation by Sex, Age, and Race. International Journal of Obesity (London), 30, 513-519. http://dx.doi.org/10.1038/sj.ijo.0803122

[15] Clum, G.A., Rice, J.C., Broussard, M., Johnson, C.C. and Webber, L.S. (2014) Associations between Depressive Symptoms, Self-Efficacy, Eating Styles, Exercise and Body Mass Index in Women. Journal of Behavioral Medicine, 37, 577-586. http://dx.doi.org/10.1007/s10865-013-9526-5

[16] Goulet, J., Provencher, V., Piche, M.E., Lapointe, A., John Weisnagel, S., Nadeau, A., Bergeron, J. and Lemieux, S. (2008) Relationship between Eating Behaviours and Food and Drink Consumption in Healthy Postmenopausal Women in a Real-Life Context. British Journal of Nutrition, 100, 910-917. http://dx.doi.org/10.1017/S0007114508925459

[17] Provencher, V., Drapeau, V., Tremblay, A., Despres, J.P. and Lemieux, S. (2003) Eating Behaviors and Indexes of Body Composition in Men and Women from the Quebec Family Study. Obesity Research, 11, 783-792. http://dx.doi.org/10.1038/oby.2003.109

[18] Lindroos, A.K., Lissner, L., Mathiassen, M.E., Karlsson, J., Sullivan, M., Bengtsson, C. and Sjostrom, L. (1997) Dietary Intake in Relation to Restrained Eating, Disinhibition, and Hunger in Obese and Nonobese Swedish Women. Obesity Research, 5, 175-182. http://dx.doi.org/10.1002/j.1550-8528.1997.tb00290.x

[19] Williamson, D.A., Lawson, O.J., Brooks, E.R., Wozniak, P.J., Ryan, D.H., Bray, G.A. and Duchmann, E.G. (1995) Association of Body Mass with Dietary Restraint and Disinhibition. Appetite, 25, 31-41. http://dx.doi.org/10.1006/appe.1995.0039

[20] Westenhoefer, J., Stunkard, A.J. and Pudel, V. (1999) Validation of the Flexible and Rigid Control Dimensions of Dietary Restraint. International Journal of Eating Disorders, 26, 53-64. http://dx.doi.org/10.1002/(SICI)1098-108X(199907)26:1<53::AID-EAT7>3.0.CO;2-N

[21] Hays, N.P., Bathalon, G.P., McCrory, M.A., Roubenoff, R., Lipman, R. and Roberts, S.B. (2002) Eating Behavior Correlates of Adult Weight Gain and Obesity in Healthy Women Aged 55 - 65 y. The American Journal of Clinical Nutrition, 75, 476-483.

[22] Dykes, J., Brunner, E.J., Martikainen, P.T. and Wardle, J. (2004) Socioeconomic Gradient in Body Size and Obesity among Women: The Role of Dietary Restraint, Disinhibition and Hunger in the Whitehall II Study. I International Journal of Eating Disorders, 28, 262-268. http://dx.doi.org/10.1038/sj.ijo.0802523

[23] French, S.A., Epstein, L.H., Jeffery, R.W., Blundell, J.E. and Wardle, J. (2012) Eating Behavior Dimensions. Associations with Energy Intake and Body Weight. A Review. Appetite, 59, 541-549. http://dx.doi.org/10.1016/j.appet.2012.07.001

[24] Werrij, M.Q., Mulkens, S., Hospers, H.J. and Jansen, A. (2006) Overweight and Obesity: The Significance of a Depressed Mood. Patient Education and Counseling, 62, 126-131. http://dx.doi.org/10.1016/j.pec.2005.06.016

[25] Bégin, C., De Grandpré, S. and Gagnon-Girouard, M.P. (2012) Eating and Psychological Profiles of Women with Higher Depressive Symptoms Who Are Trying to Lose Weight. Journal of Obesity, 2012, Article ID: 846401. http://dx.doi.org/10.1155/2012/846401

[26] Gagnon-Girouard, M.P., Begin, C., Provencher, V., Tremblay, A., Boivin, S. and Lemieux, S. (2009) Can We Apply the Dual-Pathway Model of Overeating to a Population of Weight-Preoccupied Overweight Women? International Journal of Eating Disorders, 42, 244-252. http://dx.doi.org/10.1002/eat.20614

[27] Gagnon-Girouard, M.P., Begin, C., Provencher, V., Tremblay, A., Boivin, S. and Lemieux, S. (2010) Subtyping Weight-Preoccupied Overweight/Obese Women along Restraint and Negative Affect. Appetite, 55, 742-745. http://dx.doi.org/10.1016/j.appet.2010.09.011

[28] Provencher, V., Begin, C., Gagnon-Girouard, M.P., Tremblay, A., Boivin, S. and Lemieux, S. (2008) Personality Traits in Overweight and Obese Women: Associations with BMI and Eating Behaviors. Eating Behaviors, 9, 294-302. http://dx.doi.org/10.1016/j.eatbeh.2007.10.004

[29] Camilleri, G.M., Mejean, C., Kesse-Guyot, E., Andreeva, V.A., Bellisle, F., Hercberg, S. and Peneau, S. (2014) The Associations between Emotional Eating and Consumption of Energy-Dense Snack Foods Are Modified by Sex and 
Depressive Symptomatology. Journal of Nutrition, 144, 1264-1273. http://dx.doi.org/10.3945/jn.114.193177

[30] Jansen, A., Vanreyten, A., van Balveren, T., Roefs, A., Nederkoorn, C. and Havermans, R. (2008) Negative Affect and Cue-Induced Overeating in Non-Eating Disordered Obesity. Appetite, 51, 556-562. http://dx.doi.org/10.1016/j.appet.2008.04.009

[31] Tylka, T.L. (2006) Development and Psychometric Evaluation of a Measure of Intuitive Eating. Journal of Counseling Psychology, 53, 226-240. http://dx.doi.org/10.1037/0022-0167.53.2.226

[32] Madden, C.E., Leong, S.L., Gray, A. and Horwath, C.C. (2012) Eating in Response to Hunger and Satiety Signals Is Related to BMI in a Nationwide Sample of 1601 Mid-Age New Zealand Women. Public Health Nutrition, 1-8. http://dx.doi.org/10.1017/s1368980012000882

[33] Crawford, G.B., Khedkar, A., Flaws, J.A., Sorkin, J.D. and Gallicchio, L. (2011) Depressive Symptoms and Self-Reported Fast-Food Intake in Midlife Women. Preventive Medicine, 52, 254-257. http://dx.doi.org/10.1016/j.ypmed.2011.01.006

[34] Sarlio-Lahteenkorva, S., Lahelma, E. and Roos, E. (2004) Mental Health and Food Habits among Employed Women and Men. Appetite, 42, 151-156. http://dx.doi.org/10.1016/j.appet.2003.08.014

[35] Grossniklaus, D.A., Dunbar, S.B., Tohill, B.C., Gary, R., Higgins, M.K. and Frediani, J. (2010) Psychological Factors Are Important Correlates of Dietary Pattern in Overweight Adults. European Journal of Cardiovascular Nursing, 25, 450-460. http://dx.doi.org/10.1097/JCN.0b013e3181d25433

[36] Kuczmarski, M.F., Cremer Sees, A., Hotchkiss, L., Cotugna, N., Evans, M.K. and Zonderman, A.B. (2010) Higher Healthy Eating Index-2005 Scores Associated with Reduced Symptoms of Depression in an Urban Population: Findings from the Healthy Aging in Neighborhoods of Diversity across the Life Span (HANDLS) Study. Journal of the American Dietetic Association, 110, 383-389. http://dx.doi.org/10.1016/j.jada.2009.11.025

[37] Appelhans, B.M., Whited, M.C., Schneider, K.L., Ma, Y., Oleski, J.L., Merriam, P.A., Waring, M.E., Olendzki, B.C., Mann, D.M., Ockene, I.S. and Pagoto, S.L. (2012) Depression Severity, Diet Quality, and Physical Activity in Women with Obesity and Depression. Journal of the Academy of Nutrition and Dietetics, 112, 693-698. http://dx.doi.org/10.1016/j.jand.2012.02.006

[38] Côté, D. and Mongeau, L. (2003) Le programme Choisir de maigrir? Guide pour les intervenantes et les intervenants, Québec.

[39] Bacon, L. and Aphramor, L. (2011) Weight Science: Evaluating the Evidence for a Paradigm Shift. Nutrition Journal, 10, 9. http://dx.doi.org/10.1186/1475-2891-10-9

[40] Beck, A.T., Steer, R.A. and Brown, G.K. (1996) Manual for the Beck Depression Inventory-II. Psychological Corporation, San Antonio.

[41] Labonte, M.E., Cyr, A., Baril-Gravel, L., Royer, M.M. and Lamarche, B. (2012) Validity and Reproducibility of a Web-Based, Self-Administered Food Frequency Questionnaire. European Journal of Clinical Nutrition, 66, 166-173. http://dx.doi.org/10.1038/ejcn.2011.163

[42] Stunkard, A.J. and Messick, S. (1985) The Three-Factor Eating Questionnaire to Measure Dietary Restraint, Disinhibition and Hunger. Journal of Psychosomatic Research, 29, 71-83. http://dx.doi.org/10.1016/0022-3999(85)90010-8

[43] Laessle, R.G., Tuschl, R.J., Kotthaus, B.C. and Pirke, K.M. (1989) A Comparison of the Validity of Three Scales for the Assessment of Dietary Restraint. Journal of Abnormal Psychology, 98, 504-507. http://dx.doi.org/10.1037/0021-843X.98.4.504

[44] Lluch, A. (1995) Identification des conduites alimentaires par approches nutritionnelles et psychométriques: Implications thérapeutiques et préventives dans l’obésité humaines. Ph.D. Thesis, Université Henri Poincaré, Nancy.

[45] Baron, R.M. and Kenny, D.A. (1986) The Moderator-Mediator Variable Distinction in Social Psychological Research: Conceptual, Strategic, and Statistical Considerations. Journal of Personality and Social Psychology, 51, 1173-1182. http://dx.doi.org/10.1037/0022-3514.51.6.1173. 
Scientific Research Publishing (SCIRP) is one of the largest Open Access journal publishers. It is currently publishing more than 200 open access, online, peer-reviewed journals covering a wide range of academic disciplines. SCIRP serves the worldwide academic communities and contributes to the progress and application of science with its publication.

Other selected journals from SCIRP are listed as below. Submit your manuscript to us via either submit@scirp.org or Online Submission Portal.
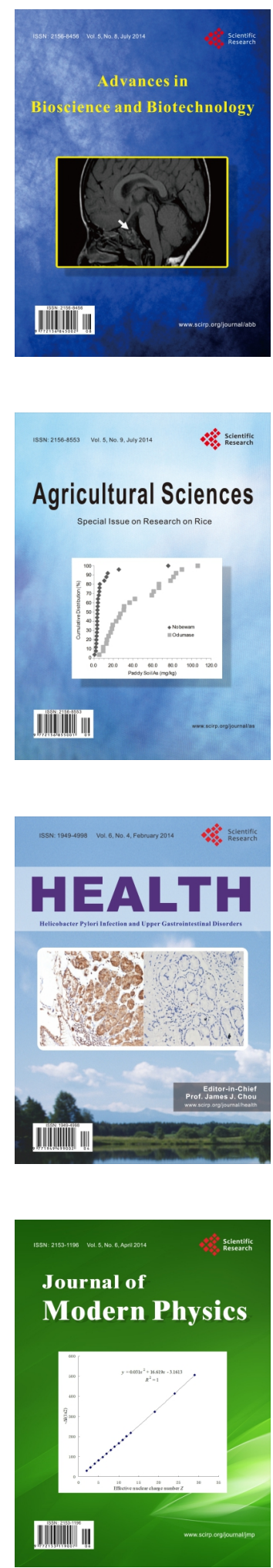
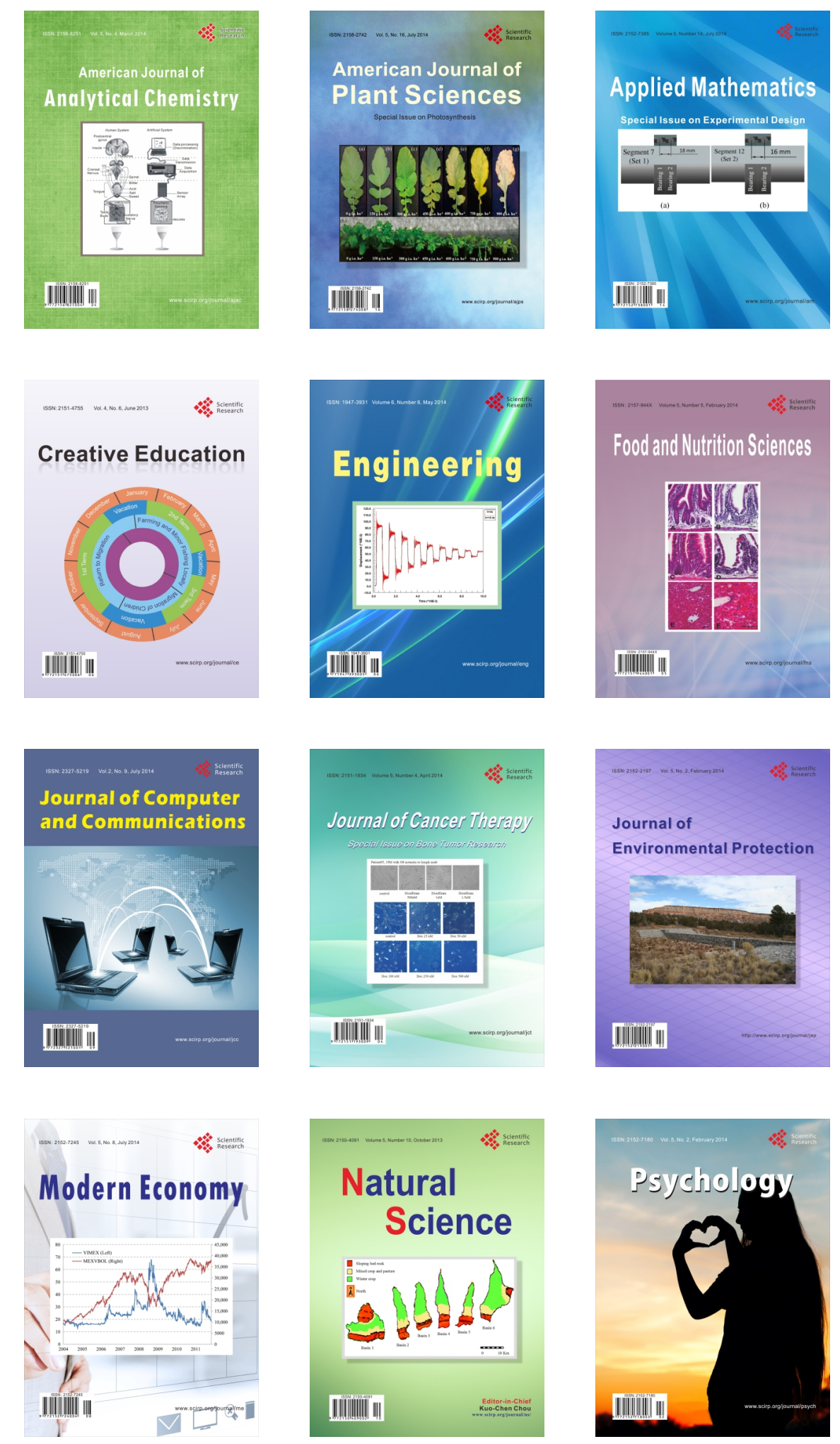